\title{
Pemilihan Karyawan Terbaik Menggunakan Metode Simple Additive Weighting (SAW) pada Perusahaan Investasi Emas
}

\author{
Anang Kurniawan', Reva Ragam Santika² \\ ${ }^{1}$ Program Studi Teknik Informatika, Universitas Budi Luhur, Jl. Ciledug Raya, RT.10/RW.2, \\ Petukangan Utara, Kec. Pesanggrahan, Kota Jakarta Selatan, Daerah Khusus Ibukota Jakarta, Indonesia, \\ 12260 \\ e-mail: ${ }^{1} 1611510163 @$ student.budiluhur.ac.id, ${ }^{2}$ reva.ragam@budiluhur.ac.id
}

Submitted Date: May $31^{\text {st }}, 2020$

Revised Date: June $30^{\text {th }}, 2020$
Reviewed Date: June $16^{\text {th }}, 2020$

Accepted Date: June $30^{\text {th }}, 2020$

\begin{abstract}
In the assessment for the determination of the best employee is still done manually, and the lack of determination for the best employee. This study aims to build a decision support system for determining the best employees in accordance with what is expected by the company. The method used in this study is Simple Additive Weighting (SAW) with the provisions of predetermined criteria, namely, order, discipline, absenteeism, cooperation, creativity. This system was developed with the PHP programming language and also uses MySQL. From the results obtained manually accuracy with a percentage of $60 \%$, While the results obtained from the accuracy of using the system reached $73.33 \%$, namely the output of the system is able to choose one of the best employees. So, it can be concluded that this research can be used as a tool to determine the best employees so that the level of employee productivity can be better and can be beneficial for the company.
\end{abstract}

Keywords: Decision Support System; Prototype; Simple Additive Weighting (SAW); The Best Employee Admission

\begin{abstract}
Dalam penilaian untuk penentuan karyawan terbaik masih dilakukan secara manual, dan kurangnya untuk penentuan karyawan terbaik. Penelitian ini bertujuan untuk membangun suatu sistem pendukung keputusan penentuan karyawan terbaik sesuai dengan apa yang diharapkan oleh pihak perusahaan. Metode yang digunakan dalam penelitian ini adalah Simple Additive Weighting (SAW) dengan ketentuan-ketentuan kriteria yang sudah ditetapkan yaitu, ketertiban, kedisplinan, absensi, kerjasama, kreativitas. Sistem ini dikembangkan dengan bahasa pemprograman PHP dan juga menggunakan MySQL. Dari hasil yang didapat akurasi secara manual dengan presentase sebesar 60\%, Sedangkan hasil yang didapat dari akurasi menggunakan sistem mencapai $73,33 \%$, yaitu hasil keluaran pada sistem mampu memilih salah satu karyawan yang terbaik. Jadi, dapat disimpulkan bahwa penelitian ini dapat dijadikan alat bantu untuk menentukan karyawan terbaik agar tingkat produktifitas karyawan bisa lebih baik dan dapat menguntungkan bagi perusahaan.
\end{abstract}

Keywords: Prototype; Simple Additive Weighting (SAW); Sistem Penunjang Keputusan; Pemilihan Karyawan Terbaik

\section{Pendahuluan}

Semakin berkembangya teknologi, persaingan antara perusahaan akan meningkatkan kualitas pada perusahaan itu sendiri. Maka hal tersebut akan menimbulkan persaingan yang mengakibatan setiap perusahaan harus melakukan peningkatan pada karyawan. Salah satu cara yang digunakan yaitu dalam menentukan karyawan terbaik. Pemilihan karyawan terbaik merupakan suatu aspek yang sangat penting pada perusahaan maka akan berpengaruh pada tingkat produktivitas karyawan sehingga mejadikan karyawan yang memiliki produktivitas serta menghasilkan pemimpin perusahaan yang memiliki integritas 
yang baik. Perusahaan tersebut kenyataannya masih belum bisa memberikan penentuan dalam menentukan karyawan terbaik. Kendala tersebut disebabkan belum adanya sistem yang dapat membantu memberikan rekomendasi kepada perusahaan untuk menentukan karyawan terbaik (Astuti \& Isna Zahrotul Fu'ad, 2017) (Penta, Siahaan, \& Sukamana, 2019).

Untuk menentukan penyeleksian karyawan pada perusahaan biasanya membutuhkan sistem yang dapat berfungsi otomatis agar tidak memakan waktu yang begitu lama dan mengurangi kesalahan yang terjadi dalam menentukan karyawan yang berhak dipilih menjadi karyawan terbaik, maka untuk menyeleksi penerimaan karyawan terbaik maka dibutuhkan bobot atau kriteria yang lebih spesifik (Abadi \& Latifah, 2016) (Primahudi, Suciono, \& Widodo, 2016).

Pada saat sebelum menggunakan sistem komputer yang sudah disediakan saat ini, proses perhitungan untuk mendapatan karyawan terbaik masih dilakukan secara manual. Hal ini menjadi penyebab kurangnya akurasi dalam perhitungan. Tentu saja permasalahan ini akan menghambat perusahaan dalam menentukan siapa karyawan yang terbaik di antara semua karyawan yang bekerja di perusahaan tersebut.

Sistem pendukung keputusan merupakan suatu bagian dari sistem informasi berbasis komputer yang dapat menyelesaikan suatu permasalahan. Diselesaikan dengan pengumpulan data informasi Sistem interaktif yang dapat membantu suatu sistem pengambilan keputusan melalui penggunaan data dan model-model keputusan agar dapat menyelesaikan suatu permasalahan (Pudoli, Kusumaningsih, \& Wahyudi, 2017) (Rikki, Maebun, \& Siregar, 2016).

Tujuan dari penelitian ini adalah membangun suatu sistem pendukung keputusan untuk menentukan pemilihan karyawan terbaik dengan metode (Simple Additive Weighting) SAW. Untuk mengetahui pegawai berprestasi dan kemudian memberikan penghargaan, agar yang diharapkan oleh perusahaan dapat mencapai tujuan serta bisa meningkatkan kualitas kerja (Sundari \& Taufik, 2014).

Berdasarkan dari uraian di atas, maka peneliti tertarik untuk mengambil permasalahan ini sebagai judul dari penelitian yang berjudul sistem penunjang keputusan penerimaan karyawan terbaik menggunakan metode (Simple Additive Weighting) SAW.

\section{Metodologi Penelitian}

Prototype merupakan pengembangan perangkat lunak, metode prototype, sesuai dengan mekanisme model prototype, dibagi menjadi 3 tahapan dalam pembuatannya:

1. Pengumpulan Informasi

Mengumpulkan suatu informasi dari suatu perusahaan mengenai tentang kebutuhan pada sistem apa saja yang diinginkan dan juga mencari tahu tentang sistem yang sedang berjalan sebelumnya agar dapat diketahui permasalah yang terdapat pada perusahaan.

2. Merancang dan membuat Prototype Pada proses ini peneliti melakukan perancangan dengan simple additive weighting. Peneliti juga akan membuat Prototype berbasis web yang akan diberikan kepada perusahaan yang bergerak di bidang investasi emas.

3. Uji Coba

Pada tahap pengujian saat ini menggunakan black box testing agar didapat hasil kekurangan dan kebutuhan, serta mendengarkan keluhan dari perusahaan. Jadi, black box testing ialah teknik suatu pengujian yang berfokus pada fungsional dari sistem (Jan, Shah, Johar, \& Khan, 2016) (Purnomo, 2017).

Sistem Pendukung Keputusan yang akan dibangun menggunakan model pengembangan waterfall (air terjun). Adapun tahapan-tahapan yang digunakan sebagai berikut:

1. Analisis Kebutuhan Sistem

Pada pengembangan tahap analisis pengembangan sistem membutuhkan pembahasan beberapa kebutuhan atau persyaratan seperti; masukan, proses dan keluaran.

2. Desain

Proses pada suatu perancangan dapat meliputi penyusunan program dan perancangan antarmuka (user interface) untuk keperluan interaksi sistem dengan pengguna (user).

3. Coding

Pada tahap coding atau penulisan bahasa program yang dapat diterjemahkan atau diartikan oleh bahasa komputer, hal berikut biasa dilakukan oleh seorang programmer.

4. Testing

Proses pengujian meliputi data kriteria dan subkriteria serta data perbandingan 
berpasangan sebagai masukan (input) pada Sistem Pendukung Keputusan sehingga menghasilkan nilai akhir sebagai pertimbangan pengambilan keputusan.
Data masukan secara manual di perusahaan investasi emas dapat dilihat pada Tabel 1 (Cahyono \& Hadikurniawati, 2019).

Tabel 1. Data masukan manual

\begin{tabular}{|c|l|c|c|c|c|c|}
\hline Pemilihan ke & Karyawan & Ketertiban & Kedisiplinan & Absensi & Kerjasama & Kreativitas \\
\hline 1 & Anang & 6 & 8 & 8 & 2 & 10 \\
\hline 1 & Bella & 8 & 2 & 2 & 10 & 4 \\
\hline 1 & Husnul & 10 & 2 & 4 & 6 & 6 \\
\hline 1 & Melby & 4 & 8 & 10 & 10 & 10 \\
\hline 1 & Vanessa & 4 & 8 & 10 & 8 & 8 \\
\hline 2 & Anang & 4 & 8 & 10 & 10 & 10 \\
\hline 2 & Bella & 4 & 8 & 10 & 8 & 8 \\
\hline 2 & Husnul & 6 & 8 & 8 & 2 & 10 \\
\hline 2 & Melby & 8 & 2 & 2 & 10 & 4 \\
\hline 2 & Vanessa & 10 & 2 & 4 & 6 & 6 \\
\hline 3 & Anang & 4 & 8 & 10 & 10 & 10 \\
\hline 3 & Bella & 6 & 8 & 8 & 2 & 10 \\
\hline 3 & Husnul & 10 & 2 & 4 & 6 & 6 \\
\hline 3 & Melby & 4 & 8 & 10 & 8 & 8 \\
\hline 3 & Vanessa & 4 & 8 & 10 & 10 & 10 \\
\hline
\end{tabular}

\section{Hasil dan Pembahasan}

A. Penerapan Metode Simple Additive Weighting (SAW)

Simple Additive Weighting (SAW)pada penelitian ini digunakan untuk menentukan karyawan terbaik berdasarkan ranking tertinggi. Berikut adalah langkah-langkahnya:

1. Menentukan Kriteria

Terdapat 5 kriteria atau bobot yang dapat dinilai yaitu ketertiban, kedisplinan, absensi, Kerjasama, dan kreativitas, lalu pihak perusahan memberikan nilai pada setiap kriteria

Tabel 2. Kriteria Karyawan

\begin{tabular}{|c|c|c|}
\hline Nama Kriteria & $\begin{array}{c}\text { Tipe } \\
\text { Kriteria }\end{array}$ & $\begin{array}{c}\text { Bobot nilai } \\
\text { Kriteria }\end{array}$ \\
\hline (C1) Ketertiban & Benefit & 25 \\
\hline (C2) Kedisiplinan & Benefit & 30 \\
\hline (C3) Absensi & Cost & 10 \\
\hline (C4) Kerjasama & Benefit & 20 \\
\hline (C5) Kreativitas & Benefit & 15 \\
\hline
\end{tabular}

2. Alternatif Karyawan

Pada tabel alternatif terdiri dari lima data yang dapat dimasukkan ke dalam tabel nilai pada setiap kriteria.
Tabel 3. Alternatif Karyawan

\begin{tabular}{|c|c|}
\hline Alternatif & Keterangan \\
\hline A1 & Anang \\
\hline A2 & Husnul \\
\hline A3 & Bela \\
\hline A4 & Melby \\
\hline A5 & Vanessa \\
\hline
\end{tabular}

3. Data Nilai Preferensi

Data ini menunjukan bahwa setiap keterangan mempunyai skor nilai.

Tabel 4. Data Nilai Preferensi

\begin{tabular}{|c|c|}
\hline Keterangan & Skor Nilai \\
\hline Sangat Buruk & 2 \\
\hline Buruk & 4 \\
\hline Cukup Baik & 6 \\
\hline Baik & 8 \\
\hline Sangat Baik & 10 \\
\hline
\end{tabular}

4. Data Nilai Alternatif Kriteria

Dan berikut adalah hasil dari penilaian alternatif kriteria yang didapat dari pihak perusahaan, yang sudah dimasukkan. 
Tabel 5. Nilai Alternatif Kriteria

\begin{tabular}{|c|c|c|c|c|c|}
\hline \multirow{2}{*}{ Alternatif } & \multicolumn{5}{|c|}{ Kriteria } \\
\cline { 2 - 6 } & C1 & C2 & C3 & C4 & C5 \\
\hline A1 & 6 & 8 & 8 & 2 & 10 \\
\hline A2 & 8 & 2 & 8 & 10 & 4 \\
\hline A3 & 10 & 2 & 4 & 6 & 6 \\
\hline A4 & 4 & 4 & 10 & 8 & 10 \\
\hline A5 & 4 & 8 & 10 & 10 & 8 \\
\hline
\end{tabular}

5. Perhitungan Nomalisasi

Setelah ditentukan nilai alternatif kriteria, maka selanjutnya melakukan perhitungan normalisasi $\mathrm{R}$.

Tabel 6. Perhitungan Normalisasi

\begin{tabular}{|c|c|c|c|c|c|}
\hline \multirow{2}{*}{ Alternatif } & \multicolumn{5}{|c|}{ Kriteria } \\
\cline { 2 - 6 } & C1 & C2 & C3 & C4 & C5 \\
\hline A1 & $6 / 10=0,6$ & $8 / 8=1$ & $4 / 8=0,5$ & $2 / 10=0,2$ & $10 / 10=1$ \\
\hline A2 & $8 / 10=0,8$ & $2 / 8=0,25$ & $4 / 8=0,5$ & $10 / 10=1$ & $4 / 10=0,4$ \\
\hline A3 & $10 / 10=1$ & $2 / 8=0,25$ & $4 / 4=1$ & $6 / 10=0,6$ & $6 / 10=0,6$ \\
\hline A4 & $4 / 10=0,4$ & $8 / 8=1$ & $4 / 10=0,4$ & $8 / 10=0,8$ & $10 / 10=1$ \\
\hline A5 & $4 / 10=0,4$ & $8 / 8=1$ & $4 / 10=0,4$ & $10 / 10=1$ & $8 / 10=0.8$ \\
\hline
\end{tabular}

6. Perhitungan Ranking

Dari hasil normalisasi, dapat dilakukan perhitungan ranking agar dapat menghasilkan siapa yang menjadi karyawan terbaik.

Tabel 7. Hasil Perhitungan Ranking

\begin{tabular}{|c|c|c|c|}
\hline Alternatif & Perhitungan dari Setiap Kriteria \& bobot nilai kriteria & Jumlah & Ranking \\
\hline A1 & $(25 \times 0,6)+(30 \times 1)+(10 \times 0,5)+(20 \times 0,2)+(15 \times 1)$ & 69 & 3 \\
\hline A2 & $(25 \times 0,8)+(30 \times 0,25)+(10 \times 0,5)+(20 \times 1)+(15 \times 0,4)$ & 58,5 & 5 \\
\hline A3 & $(25 \times 1)+(30 \times 0,25)+(10 \times 1)+(20 \times 0,6)+(15 \times 0,6)$ & 63,5 & 4 \\
\hline A4 & $(25 \times 0,4)+(30 \times 1)+(10 \times 0,4)+(20 \times 0,8)+(15 \times 1)$ & 75 & 2 \\
\hline A5 & $(25 \times 0,4)+(30 \times 1)+(10 \times 0,4)+(20 \times 1)+(15 \times 0,8)$ & 76 & 1 \\
\hline
\end{tabular}

Berdasarkan pada tabel 6, bahwa yang ditentukan sebagai karyawan terbaik adalah A5, yaitu Vanessa.

\section{B. Use Case Diagram}

Use Case Diagram adalah penjelasan tentang kebutuhan suatu sistem dari sisi HRD dan Manajer yang Merupakan pola dan perilaku sistem. 


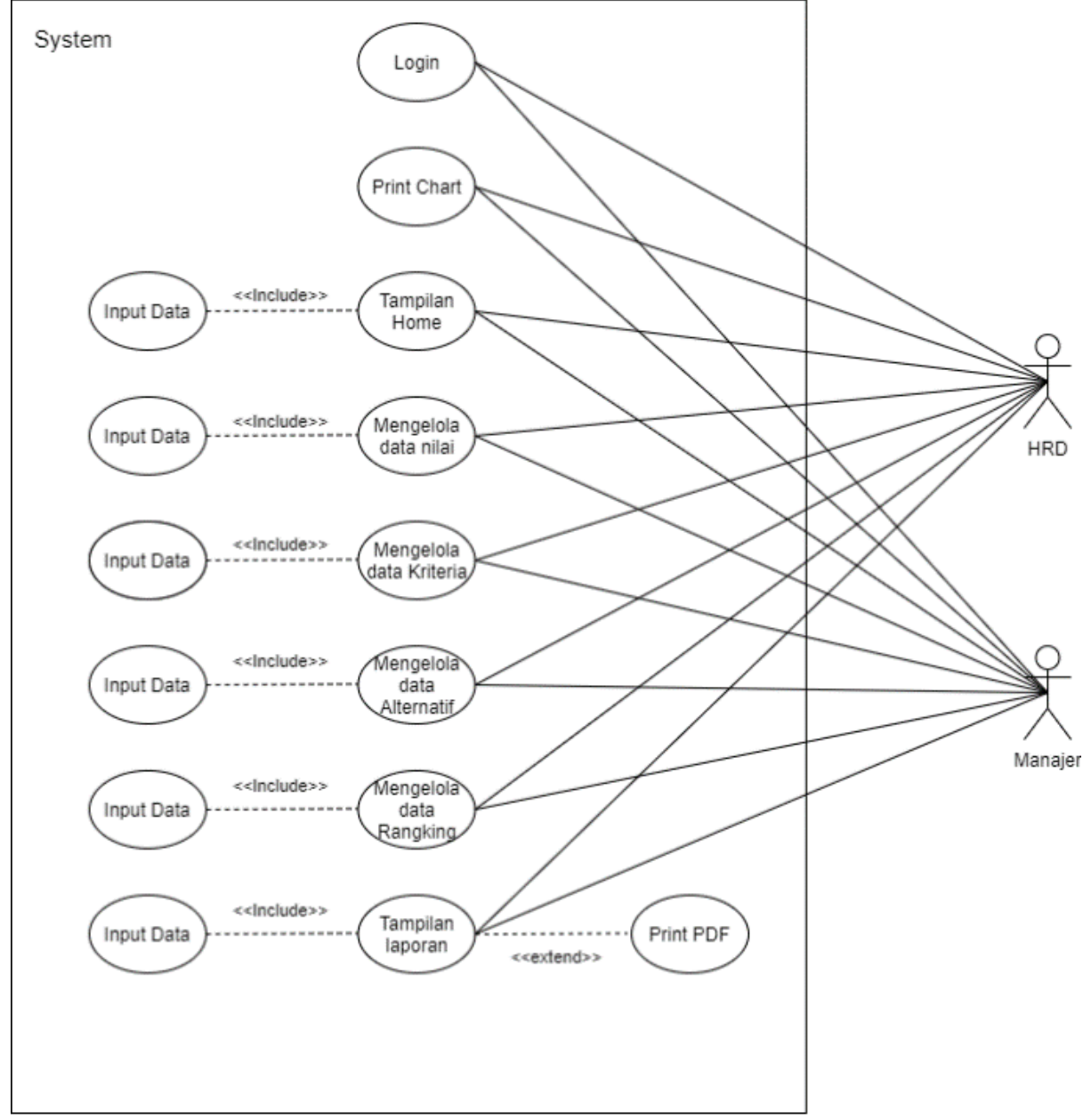

Gambar 1. Use Case Diagram

\section{Tampilan Layar}

Pembahasan pada tampilan layar yang dilakukan oleh peneliti ialah, tampilan berupa halaman aplikasi yang bertujuan untuk memasukkan data sampai dengan menampilkan hasil untuk penentuan karyawan terbaik.

\section{Tampilan Data Nilai Preferensi}

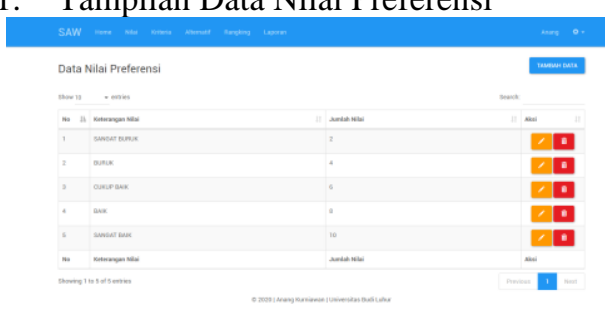

Gambar 2. Data Nilai Preferensi

Pada tampilan gambar 2 di atas adalah menjelaskan bagaimana proses memasukkan data nilai preferensi yang berupa keterangan kriteria dan jumlah nilai. Sehingga dapat menghasilkan data berupa, sangat buruk, buruk, cukup baik, baik, sangat baik dan jumlah nilai.

\section{Tampilan Data Kriteria}

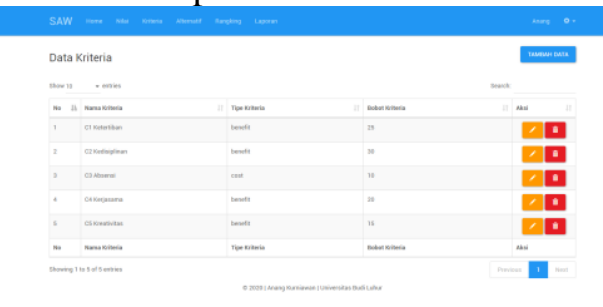

Gambar 3. Data Nilai Ktriteria

Pada tampilan gambar 3 di atas adalah menjelaskan bagaimana proses memasukkan data nilai kriteria, seperti nama kriteria, tipe kriteria, dan bobot kriteria. sehingga dapat menampilkan data kriteria berupa kode kriteria $\mathrm{C} 1$ sampai dengan $\mathrm{C} 5$, tipe kriteria yaitu benefit dan cost, dan nilai bobot kriteria. 


\section{Tampilan Data Alternatif}

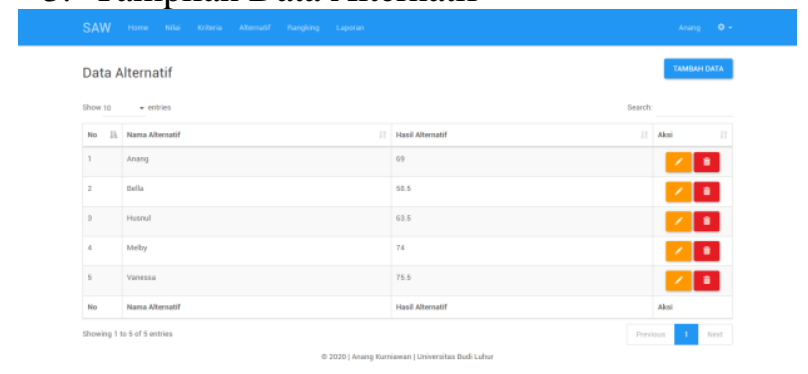

Gambar 4. Data Nilai Alternatif

Pada tampilan gambar 3 di atas adalah menjelaskan bagaimana proses memasukkan pada data alternatif. Dengan proses ini maka data yang ditampilkan pada form data alternatif adalah namanama karyawan dan hasil nilai alternatif yang didapatkan pada proses perhitungan antara form data kriteria dan data nilai preferensi

\section{Tampilan Data Ranking}

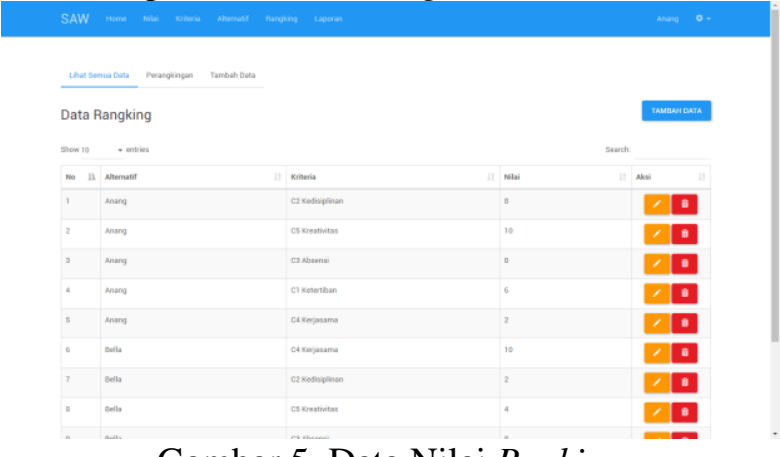

Gambar 5. Data Nilai Ranking

Pada tampilan gambar 4 di atas adalah menjelaskan bagaimana proses pemilihan data ranking, dengan nama data-data yang di tampilkan adalah Alternatif, kriteria, dan nilai, maka program yang akan ditampilkan pada form data ranking adalah nama karyawan, kriteria, dan nilai.

5. Tampilan Laporan

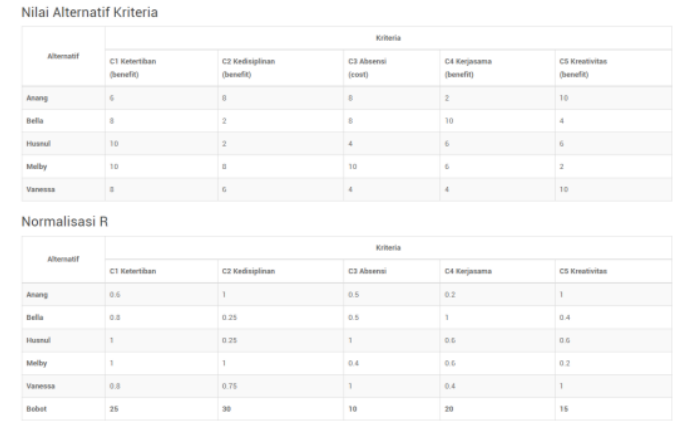

Gambar 6. Tampilan Laporan

Pada tampilan gambar 6 diatas adalah menjelaskan bagaimana menampilkan data hasil perhungan dengan metode Simple Additive Weighting (SAW)

\section{Hasil Uji}

Pada tahap ini penguji bertujuan untuk mengetahui kekurangan dari sistem yang telah dibangun. Pada fase penelitian ini menggunakan metode BlackBox untuk pengujian sistem pada tahap akhir.

- Black box login

Black box login user ialah berfungsi untuk menjelesakan proses button login HRD ataupun Manajer pada tampilan login pada sistem, seperti tabel di bawah ini:

Tabel 8. Pengujian Black Box Login

\begin{tabular}{|c|c|l|l|c|}
\hline No & Button & \multicolumn{1}{|c|}{ Scenario pengujian } & \multicolumn{1}{|c|}{ Hasil Uji yang diharapkan } & Hasil \\
\hline \multirow{3}{*}{1} & \multirow{3}{*}{\begin{tabular}{c} 
login \\
\cline { 3 - 4 }
\end{tabular}} & $\begin{array}{l}\text { Mengisi user dan password tetapi tidak } \\
\text { sesuai dengan isi data base lalu klik } \\
\text { tombol login }\end{array}$ & $\begin{array}{l}\text { Sistem menolak akses untuk login, maka } \\
\text { akan menampilkan pesan "Localhost } \\
\text { Menyatakan Gagal Total" }\end{array}$ & $\checkmark$ \\
\cline { 3 - 5 } & $\begin{array}{l}\text { Mengisi salah satu user name atau } \\
\text { password sesuai lalu klik login }\end{array}$ & $\begin{array}{l}\text { Sistem menolak akses untuk login, maka } \\
\text { akan menampilkan pesan "Localhost } \\
\text { Menyatakan Gagal Total" }\end{array}$ & $\checkmark$ \\
\cline { 3 - 5 } 3 & $\begin{array}{l}\text { Mengisi user name dan password sesuai } \\
\text { dengan data base }\end{array}$ & $\begin{array}{l}\text { Sistem menerima akses untuk login, maka } \\
\text { akan masuk ke menu home }\end{array}$ & $\checkmark$ \\
\hline
\end{tabular}

- Black box Halaman Utama

Black box halaman utama ialah berfungsi untuk menjelaskan proses button tampilan halaman utama pada sistem, seperti tabel nomor 9 di sini. 
Tabel 9. Pengujian Black Box Halaman Utama

\begin{tabular}{|c|l|l|l|c|}
\hline No & \multicolumn{1}{|c|}{ Button } & \multicolumn{1}{|c|}{ Skenario Penguji } & \multicolumn{1}{c|}{ Hasil Uji yang Diharapkan } & Hasil \\
\hline 1 & Button Home & Menu Home & Dapat di klik maka akan masuk kemenu home & $\checkmark$ \\
\hline 2 & Button Data Nilai & Menu Data Nilai & Dapat di klik maka akan masuk ke form data nilai & $\checkmark$ \\
\hline 3 & Button Data Kriteria & Menu Data Kriteria & Dapat di klik maka akan masuk ke form data kriteria & $\checkmark$ \\
\hline 4 & Button Data Alternatif & Menu Data Alternatif & Dapat di klik maka akan masuk ke form data alternatif & $\checkmark$ \\
\hline 5 & Button Ranking & Menu Ranking & Dapat di klik maka akan masuk ke form data ranking & $\checkmark$ \\
\hline 6 & Button Laporan & Menu Laporan & Dapat di klik maka akan masuk ke menu laporan & $\checkmark$ \\
\hline
\end{tabular}

\section{E. Pengujian Akurasi}

Langkah selanjutnya adalah pengujian akurasi. Langkah ini berguna untuk mendapatkan perbandingan akurasi antara penghitungan manual yang dikalukan oleh bagian HRD dan penghitungan akurasi yang dilakukan oleh sistem. Selain itu yang penting dan utama, langkah ini berfungsi untuk menyelesaikan permasalahan dalam mendapatkan karyawan terbaik di perusahaan investasi emas. Proses ini memiliki tujuan untuk mendapatkan kandidat siapa yang menjadi karyawan terbaik. Perbandingan akurasi secara manual dan sistem tersebut dapat di lihat pada tabel sebagai berikut:

Tabel 10. Tabel Pengujian Akurasi

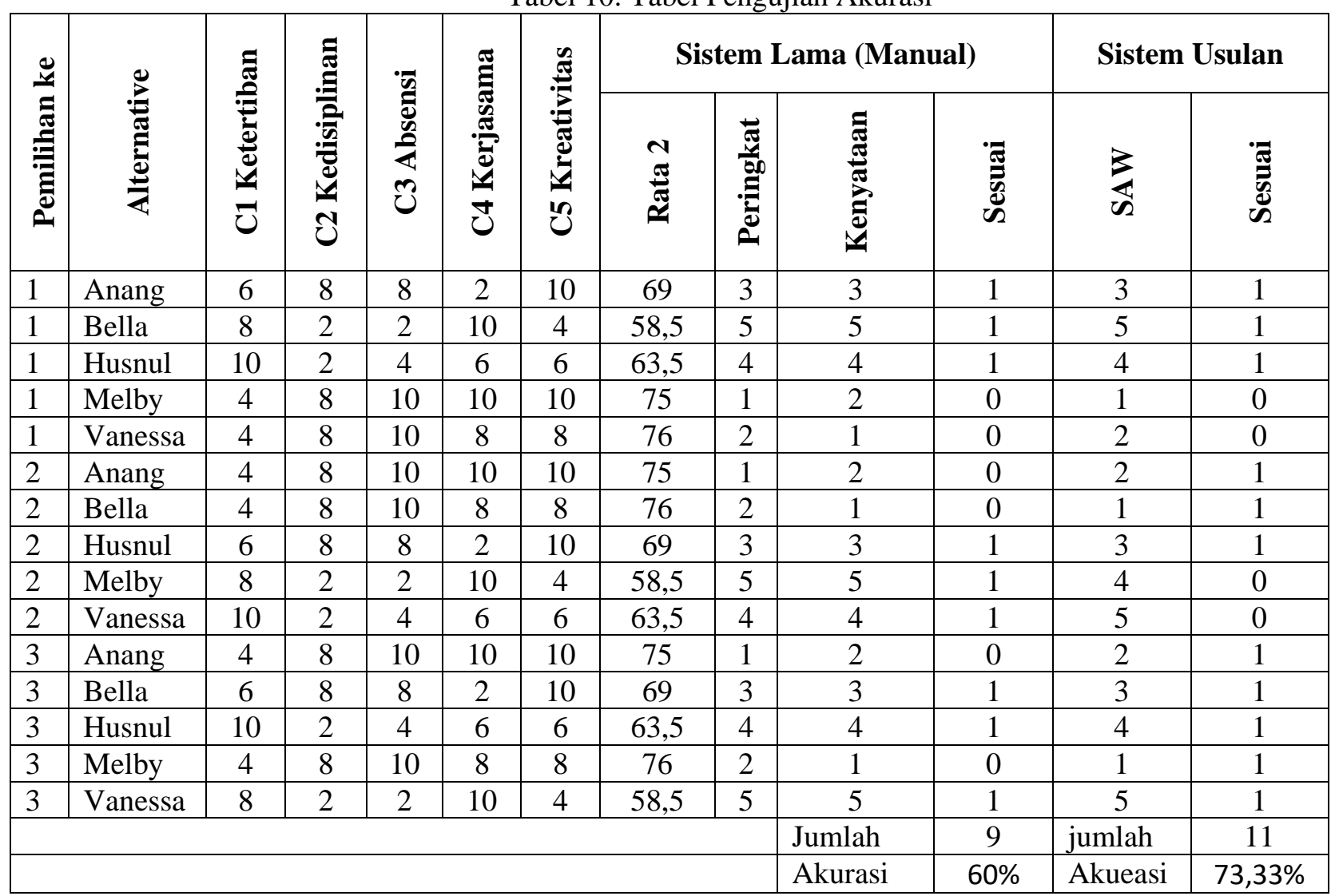

Dari pengujian sebanyak 15 kali berdasarkan tabel diatas, mendapatkan hasil akurasi yang berbeda. Perbandingan akurasi ini menggunakan nilai yang sama. Akurasi dengan manual hanya mendapatkan persentase sebesar $60 \%$, sedangkan akurasi dengan sistem adalah $73,33 \%$. Jadi dapat diambil garis besar bahwa akurasi sistem lebih layak digunakan dalam pemilihan karyawan terbaik di perusahaan invetasi emas.
Penelitian akurasi yang didapat pada metode simple additive weighting (SAW) adalah $2.46898 \%$, sedangkan menggunakan metode WP adalah sebesar $0.00668 \%$. Berdasarkan kesimpulan hasil pengujian yang dilakukan pada penelitan sebelumnya dengan menggunakan metode SAW lebih baik dari pada menggunakan metode WP, oleh sebab itu peneliti ingin menggunakan metode simple additive weighting (SAW) dalam penentuan 
karyawan terbaik pada perusahaan investasi emas (Amelia \& Prianto, 2019).

\section{Kesimpulan}

Berdasarkan pada hasil penelitian yang didapat pada sistem pendukung keputusan karyawan dengan pemilihan karyawan terbaik menggunakan metode Simple Additive Weighting (SAW), maka dapat disimpulkan bahwa:

1. Sistem yang dibuat peneliti dapat membantu pihak perusahaan dalam menentukan karyawan terbaik, membantu serta menunjang semangat kerja pada setiap karyawan untuk selalu bersaing menjadi yang terbaik diperusahaan tersebut.

2. Metode Simple Additive Weighting (SAW) digunakan karena dapat membantu mengambil suatu keputusan dalam menentukan pemilihan karyawan terbaik pada perusahaan yang bergerak dibidang investasi emas.

3. Dengan dilakukannya penelitian ini, maka perusahaan dapat memahami bagaimana proses atau prosedur yang dilakukan untuk menentukan pemilihan karyawan terbaik.

\section{Referensi}

Abadi, S., \& Latifah, F. (2016). Decision Support System Penilaian Kinerja Karyawan Pada Perusahaan Menggunakan Metode Simple Additive Weighting. Jurnal TAM (Technology Acceptance Model), 6, 37-43.

Amelia, S., \& Prianto, C. (2019). Uji Kinerja Metode Weighted Product dan Simple Additive Weighting. $7(2), 1-10$.

Astuti, Y., \& Isna Zahrotul Fu'ad. (2017). Penentuan Karyawan Terbaik Menggunakan Metode Simple Additive Weighting Pada PT. Patra Nur Alaska. Seminar Nasional Tekhnologi Informasi Dan Multimedia, 37-42. Retrieved from http://ojs.amikom.ac.id/index.php/semna steknomedia/article/view/1699/1576

Cahyono, T. D., \& Hadikurniawati, W. (2019).
Perancangan Model Waterfall Untuk Sistem Pendukung Keputusan Multi Attribute Dengan Metode Analytic Network Process. Dinamik, 23(1), 35-47.

Jan, S. R., Shah, S. T. U., Johar, Z. U., \& Khan, F. (2016). An Innovative Approach to Investigate Various Software Testing Techniques and Strategies. International Journal of Scientific Research in Science, Engineering and Technology, 2(2), 682-689.

Penta, M. F., Siahaan, F. B., \& Sukamana, S. H. (2019). Sistem Pendukung Keputusan Pemilihan Karyawan Terbaik Menggunakan Metode SAW pada PT. Kujang Sakti Anugrah. JSAI (Journal Scientific and Applied Informatics), 2(3), 185192.

Primahudi, A. B., Suciono, F. A., \& Widodo, A. A. (2016). Sistem Pendukung Keputusan Untuk Pemilihan Karyawan Dengan Metode Simple Additive Weighting Di Pt. Herba Penawar Alwahida Indonesia. J I M P - Jurnal Informatika Merdeka Pasuruan, 1(2), 57-80.

Pudoli, A., Kusumaningsih, D., \& Wahyudi, M. (2017). Penerapan Algoritma C4.5 untuk Memprediksi Masa Studi dan Predikat Lulusan S1 Akuntansi pada STIE Muhammadiyah Jakarta. Jurnal TICOM, 5(3), 181-186.

Purnomo, D. (2017). Model Prototyping Pada Pengembangan Sistem Informasi. 2(2), 54-61.

Rikki, A., Maebun, M., \& Siregar, J. R. (2016). Sistem Pendukung Keputusan Penerimaan Karyawan Dengan Metode SAW Pada PT. Karya Sahata Medan. Journal of Informatics Pelita Nusantara, $1(1), 38-46$.

Sundari, S. S., \& Taufik, Y. F. (2014). Pegawai Baru Dengan Menggunakan Metode Simple Additive Weighting ( Saw ). Sisfotenika, Vol. 4, No, 140151 . 